\title{
Evaluation of Three Mycobacterium leprae Monoclonal Antibodies in Mucus and Lymph Samples from Ziehl- Neelsen Stain Negative Leprosy Patients and their Household Contacts in an Indian Community
}

\author{
Nora Cardona-Castro ${ }^{+}$, Gustavo Ortega-Rodríguez $* / \dagger$, \\ Piedad Agudelo-Flórez
}

\begin{abstract}
Laboratorio de Microbiología, Instituto Colombiano de Medicina Tropical, Cra. 48 No. 32-102, Hospital General de Medellín Piso 4, AA 52162, Medellín, Colombia *Laboratorio de Ingeniería Genética, Instituto de

Biomedicina, Caracas 1010A, AA 4043, Venezuela
\end{abstract}

Mucus and lymph smears collected from leprosy patients (9) and their household contacts (44) in the Caño Mochuelo Indian Reservation, Casanare, Colombia, were examined with monoclonal antibodies $(M o A b)$ against Mycobacterium leprae. The individuals studied were: 5 borderline leprosy $(B B) p a-$ tients, 4 with a lepromatous leprosy $(L L)$, all of whom were undergoing epidemiological surveillance after treatment and 44 household contacts: 21 of the LL and 23 contacts of the BB patients.

The $M o A b$ were reactive with the following $M$. leprae antigens: $65 \mathrm{kd}$ heat shock protein, A6; soluble antigen $G 7$ and complete antigen, E11. All the samples were tested with each of the MoAb using the avidin-biotin-peroxidase technique and 3,3 diaminobenzidine as chromogen. The patients and household contacts studied were all recorded as Ziehl-Neelsen stain negative.

The MoAb which showed optimal reaction was $G 7$, this MoAb permited good visualization of the bacilli. Five patients with BB diagnosis and one with $L L$ were positive for G7; of the BB patients' household contacts, 9 were positive for G7; 7 of the LL patients' household contacts were positive for the same MoAb. MoAb G7 allowed the detection of bacillar Mycobacterium spp. compatible structures in both patients and household contacts. G7 permited the visualization of the complete bacillus and could be used for early diagnosis and follow-up of the disease in patients.

Key words: monoclonal antibodies - Mycobacterium leprae - lymph and mucus samples

Leprosy is a chronic granulomatous disease produced by Mycobacterium leprae. This bacillus affects the peripheral nervous system, skin, eyes and other parts of the body such as testicles and larynx. Most of the leprosy handicaps originate in the engagement of the peripheral nervous system, which causes progressive and traumatic loss of hands and legs and severe ocular damage. World leprosy control programs have established as one of their priorities, the management and early detection of patients with light clinical forms, with the aim of reducing physical handicaps. Nonetheless, between 25 and $30 \%$ of the world leprosy

\footnotetext{
This project was financed by The Third World Academy of Sciences-TWAS, Trieste, Italy and by Instituto Colombiano de Medicina Tropical, Medellín, Colombia.

${ }^{+}$Corresponding author. Fax:+57-4-262.5508. E-mail: icmt@epm.net.co

${ }^{\dagger}$ Deceased

Received 10 July 1997

Accepted 17 April 1998
}

patients show neurological complications which cause serious physical deformities (Ward 1985, Ottenhoff 1994).

The dissemination of the infection in communities depends on the opportunities of contact with the bacillus as well as the immunological response of each exposed individual. Currently, it is known that sub clinical infection by $M$. leprae in endemic areas is very frequent, but the percentage of individuals who develop the disease is low (Britton 1993, Colston 1993).

Leprosy diagnosis is made through the observation of abnormal superficial sensitivity, thickening of peripheral nerves, and visualization of the Mycobacterium itself in smears of nasal mucus, lymph and cutaneous lesions by Ziehl-Neelsen staining (bacillar index). When stained by ZiehlNeelsen method M. leprae is visualized as an acidalcohol-fast, slightly curved bacillus, 0.3-0.4 $\mu \mathrm{m}$ in length, sometimes containing a metachromatic granule near a pole or in the center (Ward 1985, Roberts et al. 1991); however this technique is not useful in the diagnosis at paucibacillary patients. 
Another diagnostic aid is the skin biopsy, which confirms clinical suspicion, establishes the diagnosis within the Ridley and Jopling classification, and guides in the diagnosis of reaction states (Ward 1985, Roberts et al. 1991).

M. leprae contains large amounts (2\% of dry weight) of a specific phenolic glycolipid (PG1), that contains a trisaccharide that apparently is unique to this organism (Ward 1985). This antigen has been used in serological tests to detect antibodies (Lafarte et al. 1991, Klatser 1994) and in the production of MoAb (Wu 1992, Liu et al. 1993). This use represents an important aid in early diagnosis of high risk and infected people, and is of great use in patients with a high bacillar load who show high levels of IgM type antibodies, but presents limitations in paucibacillar cases (Klatser 1994).

MoAb for M. leprae had been produced and offer considerable promise as immunochemical reagent that should permit far more precise identification of the bacillus (Ward 1985). MoAb are a useful tool for detecting $M$. leprae antigens in mucus, urine and cerebrospinal fluid samples and sensitivity surpassed that of the Ziehl-Neelsen stain (Patil et al. 1991, Singh et al. 1991). Several M. leprae's antigen have been used to produce MoAb: $65 \mathrm{kDa}$ heat shock protein (Kleinau et al. 1991, Hajeer et al. 1992, Rambukkana et al. 1992), 35 $\mathrm{kDa}, 33 \mathrm{kDa}, 28 \mathrm{kDa}, 23 \mathrm{kDa}, 22 \mathrm{kDa}, 10 \mathrm{kDa}$ proteins, etc. (Khanolkar-Young et al. 1992). At least $58 \mathrm{MoAb}$, have been evaluated to identify antibodies which could be recommended as standard reagents (Khanolkar-Young et al. 1992).

\section{MATERIALS AND METHODS}

Volunteers - All leprosy patients (9 in total) from the Caño Mochuelo Indian Reservation, Casanare, Colombia and their household contacts (all of them without clinical manifestations of leprosy), were studied as follows. The 9 leprosy patients belonged to the leprosy epidemiological surveillance program, i.e., patients who have finished the treatment, but continue under control, 4 with lepromitous leprosy (LL) diagnosis and 5 with borderline leprosy (BB) diagnosis. Fourty-four household contacts (members of a leprosy patient family and others living under the same roof) of the above mentioned patients distributed as follows: 21 household contacts of the LL and 23 contacts of the BB patients.

Samples - Four mucus and lymph smears were taken from the volunteers. Ziehl-Neelsen stain was performed on the first smear, according to the technique of Roberts et al. (1991) and slides were read by two observers. The remaining smears were used for immunostaining with the MoAb, and were read twice by two different observers.

Antigen preparation - The method of quantitative recovery of $M$. leprae bacilli from lymph nodes of experimentally infected armadillos, was adapted from a method developed by Draper (1981).

Ultrasonication was performed as previously described by Kolk et al. (1984), the suspension obtained was centrifugued for $1 \mathrm{hr}$ at $16.000 \mathrm{xg}$. The supernant obtained was used as the antigen source. Each specific protein was purified using the sonicated antigens of $M$. leprae applied to an affinity column (sepharose-4B).

Hybridoma technique - Balb/c mice were immunized with each one of the purified protein. Spleen cells were fused with Sp2/O-A14 mouse myeloma cells using standard techniques (Galfre \& Milstein 1984).

Monoclonal antibodies - The MoAb were produced and supplied by Dr Gustavo OrtegaRodríguez of the Instituto de Biomedicina, Caracas, Venezuela, A6 directed against a $65 \mathrm{Kd}$ heat shock protein, G7 obtained from a soluble antigen and E11 produced using complete antigen of M. leprae.

Immunostaining standardization - In order to standardize immunostainings, an isolate of $M$. chelonae was used to prepare smears. These were tested with each MoAb (A6, G7, E11) and with each type of immunostaining (immunofluorescence and avidin-biotin-peroxidase complex).

For fluorescence, antimouse IgG FITC conjugate absorbed with human serum proteins (Sigma Chemical Co., St Louis, MO) was utilized, and Evan's blue (Sigma Chemical Co., St Louis, MO) was used as counter stain (Harlow \& Lane 1988). Slides were observed using a fluorescence microscope.

Avidin-biotin-peroxidase complex (Vectastain $\mathrm{ABC}$ Kit, Vector Laboratories, Inc. Burlingame, CA), was developed with 3-amino 9-ethyl carbazole (AEC) (Sigma Chemical Co., St Louis, MO) and 3,3 diaminobenzidine tetra hydrochloride (DAB) (Sigma Chemical Co., St Louis, MO) which were tested as chromogens. In addition, endogenous peroxidase inhibition was performed treating samples with hydrogen peroxide at 3\% (JT Baker BV Deventer, Holland) (Martínez-Arends et al. 1991).

Ziehl-Neelsen stain - It was carried out according to a standardized methodology (Roberts et al. 1991).

\section{RESULTS}

Immunostaining standardization - The immunostaining technique which allowed the best reading and the lowest non-specific staining was 
the one carried out with the avidin-biotin-peroxidase complex using 3,3 diaminobenzidine as chromogen. This technique was used to test the mucus and lymph samples (Fig.)

Monoclonal antibody - The MoAb which showed optimal reaction with M. leprae was G7 because it permitted the detection of complete bacillar structures compatible with Mycobacterium spp. The other two MoAb did not permit visualization of the complete bacilli, thus impeding a conclusive interpretation.

Samples - All the Ziehl-Neelsen stained samples in patients and household contacts were negative. Immunostaining with $\mathrm{G} 7$ allowed the detection of $5(100 \%)$ patients with BB and of 9 household contacts of these patients $(42.8 \%)$. In the case of the patients with LL, one (25\%) was positive and $7(30 \%)$ household contacts were positive for G7 (Table).

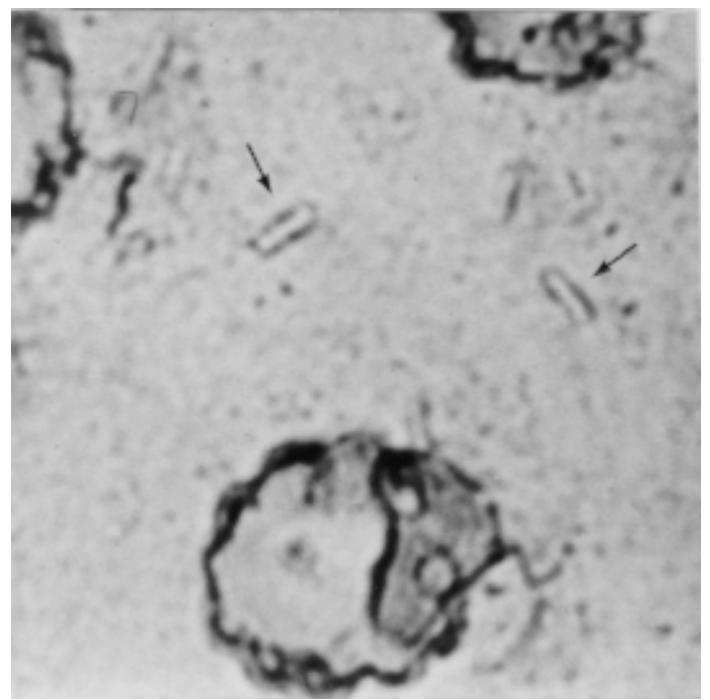

Lymph smear. G7 immunostaining. Avidin-biotin-peroxidase using DAB chromogen. 1000X.

\section{DISCUSSION}

Immunostaining with MoAb G7 may represent an appropriate tool for early diagnosis in paucibacillary patients, household contacts and follow-up of the disease in leprosy patients which have undergone therapy. Indeed, this technique detected $M$. leprae antigen in a number of samples from patients and contacts that were not detected with the Ziehl Neelsen stain.

One hundred percent of the samples immunostained with G7 MoAb, were positive for patients with BB diagnosis, and $25 \%$ of LL patients undergoing epidemiological surveillance. Ziehl-Neelsen was negative for all the patients, a result which would classify them as paucibacillar or cured, if treatment has already been completed.

The negative results for the Ziehl-Neelsen stain in patients can be explained by the limited sensitivity of the method and by the fact that the patients studied were under post-treatment epidemiological surveillance.

In future experiments, this G7 MoAb could be tested using different study populations, in patients with active infection, and in people who, due to their epidemiological conditions, have been in contact with leprosy patients.

Other MoAb had been used to detect antigen of $M$. leprae in urine and mucus samples of leprosy patients. Two types of primary antibodies, a polyclonal antibody obtained from LL patient's serum pool and an anti-PGL-I MoAb. The polyclonal antibody detected $23 \%$ to $36 \%$ of the paucibacillary and $100 \%$ of the multibacillary leprosy cases from the urine samples. The correspondig values for detection in nasal samples were $10 \%$ to $18 \%$ for paucibacillary and $100 \%$ for multibacillary cases (Singh et al. 1991).

ML 06, ML 04 and ML 24 MoAb were used to detect antigens in cerebrospinal fluid of patients

TABLE

Results of immunostaining with monoclonal antibodies (MoAb) G7 and Ziehl-Neelsen (ZN) stain in the population studied

\begin{tabular}{|c|c|c|c|c|c|c|c|}
\hline \multirow{2}{*}{$\begin{array}{l}\text { Population } \\
\text { studied }\end{array}$} & \multirow{2}{*}{$\begin{array}{c}\text { No. of } \\
\text { subjects }\end{array}$} & \multicolumn{4}{|c|}{ MoAb G7 } & \multicolumn{2}{|c|}{$\mathrm{ZN}$} \\
\hline & & $\mathrm{M}$ & $\stackrel{+}{\mathrm{L}}$ & $\mathrm{M}+\mathrm{L}$ & - & + & - \\
\hline LL patients & 4 & 0 & 0 & 1 & 3 & 0 & 4 \\
\hline BB patients & 5 & 3 & 2 & 0 & 0 & 0 & 5 \\
\hline LL patients' households & 21 & 6 & 0 & 3 & 12 & 0 & 21 \\
\hline BB patients' households & 23 & 4 & 1 & 2 & 0 & 0 & 23 \\
\hline Total & 53 & 13 & 3 & 6 & 15 & 0 & 53 \\
\hline
\end{tabular}

M: mucus sample positive; L: lymph sample positive; M+L: mucus and lymph samples positive; LL: lepromatous leprosy; BB: borderline leprosy. 
with leprosy. Antigens of $12 \mathrm{kDa}, 35 \mathrm{kDa}$ and 30 $40 \mathrm{kDa}$ were detected. This study revealed the presence of $M$. leprae antigens in the cerebrospinal fluid of leprosy patients and the probable involvement of the central nervous system in leprosy (Patil et al. 1991).

These data could be important in the application of these tests for diagnosis of paucibacillar patients, follow-up of patients undergoing treatment, epidemiological surveillance, study of household contacts and the general population in endemic areas, populations for which Ziehl-Neelsen is not a useful diagnostic tool.

\section{ACKNOWLEDGEMENTS}

To Mr William Arbelaez, nurse of the Caño Mochuelo Indian Reservation (Casanare, Colombia).

\section{REFERENCES}

Britton WJ 1993. Immunology of leprosy. Trans $R$ Soc Trop Med Hyg 87: 508-514.

Colston MJ 1993. The microbiology of Mycobacterium leprae, progress in the last 30 years. Trans $R$ Soc Trop Med Hyg 87: 504-507.

Draper P 1981. Demostration of antibodies reacting with different determinants on Mycobacterium leprae antigen 7. Int J Lepr Other Mycobact Dis 49: 147-58.

Galfre G, Milstein C 1981. Preparation of monoclonal antibodies: strategies and procedures. Methods Enzymol 73(Pt B): 3-46.

Hajeer AH, Worthington J, Morgan K, Berstein RM 1992. Monoclonal antibody epitopes of mycobacterial $65 \mathrm{kD}$ heat shock protein defined by epitope scanning. Clin Exp Immunol 89: 115-119.

Harlow E, Lane D 1988. Monoclonal antibodies, p. 139420. In E Harlow, D Lane (eds), Antibodies. A Laboratory Manual, Cold Spring Harbor Laboratory, NY.

Khanolkar-Young S, Kolk, AH, Andersen AB, Bennedsen J, Brennan PJ, Rivoire B, Kuijper S, McAdam KP, Abe C, Batra HV, Chaparas SD, Damiani G, Singh M, and Engers HD 1992. Results of the third immunology of leprosy/immunology of tuberculosis antimycobacterial monoclonal antibody workshop. Infect Immun 60: 3925-3927.

Kolk AH, Ho ML, Klatser PR, Eggelte TA, Kuijper S, de Jonge S, van Leeuwen J 1984. Production and characterization of monoclonal antibodies to $M y$ cobacterium tuberculosis, M. bovis (BCG) and M. leprae. Clin Exp Immunol 58: 511-521.

Klatser P 1994. Serology of leprosy. Trop Geogra Med 46: $115-118$.
Kleinau S, Soderstrom K, Kiessling R, Klareskog L 1991. A monoclonal antibody to the mycobacterial $65 \mathrm{kDa}$ heat shock protein (ML 30) binds to cells in normal and arthritic joints of rats. Scand J Immunol 33: 195-202.

Lafarte J, Abreu, ES, Robaina R, Verez V 1991. Ultramicroelisa para la detección de anticuerpos IgM anti Mycobacterium leprae. Rev Inst Med Trop São Paulo 33: 491-495.

Liu X, Wang D, Mu J 1993. Production and identification of monoclonal anti-idiotype antibodies against anti-phenolic glycolip-I antibody of Mycobacterium leprae. Hua Hsi I Ko Ta Hsueh Hsueh Pao 24: 254257.

Martínez-Arends A, Tapia FJ, Cáceres-Dittmar G, Mosca W, Valecillos L, Convit J 1991. Immunocytochemical characterization of immune cells in lesions of American cutaneous leishmaniasis using novel T cell markers. Acta Tropica 49: 271-280.

Ottenhoff T 1994. Immunology of leprosy: lessons from and for leprosy. Intern J Lep 62: 108-121.

Patil SA, Tyagi P, Katoch K, Streevatsa, Sengupta U 1991. Antigens of Mycobacterium leprae in the cerebrospinal fluid of leprosy patients: detection by monoclonal antibody based sandwich immunoradiometric assay and avidin/biotin immunoblotting. Clin Exp Immunol 84: 515-521.

Rambukkana A, Das PK, Burggraaf JD, Faber WR, Teeling P, Krieg S, Thole KE, Harboe M 1992. Identification and characterization of epitopes shared between the mycobacterial 65-kilodalton heat shock protein and the actively secreted antigen $85 \mathrm{com}$ plex: their in situ expression on the cell wall surface of Mycobacterium leprae. Infect Immun 60: 4517 4527.

Roberts GD, Koneman EW, Kim YK 1991. Mycobacterium, p. 304-337. In A Balows, WJ Hausler Jr KL, Herrmann HD Isenberg, HJ Shadomy (eds), Manual of Clinical Microbiology, American Society for Microbiology, Washington, D.C.

Singh NB, Chodhary A, Bhatnagar S 1991. Detection of Mycobacterium leprae specific antigens with dotELISA in urine and nasal samples from leprosy patients. Int J Lepr Other Mycobact Dis 59: 398-404.

Ward EB 1985. Mycobacterium leprae (leprosy), p. 1406-1413. In Gerald L Mandell, R Gordon Douglas, John E Bennet (eds), Principles and Practice of Infectious Diseases, New York, Chichester, Brisbane, Toronto, Singapure.

Wu QX 1992. Production of monoclonal antibodies against Mycobacterium leprae. Chung Hua I Hssueh Tsa Chih Taipei 72: 683-685. 